\section{SAT0152 EFFECTS OF RALOXIFENE ON BONE MINERAL DENSITY AND ON SERUM LIPIDS IN POSTMENOPAUSAL WOMEN WITH SEVERE OSTEOPENIA AND/OR OSTEOPOROSIS}

A Matsoyka, E Kantaxaki, S Zerboudis, A Georgiadis. Osteoporosis Center, Gynecological Hospital "LITO", Athens, Greece

\subsection{6/annrheumdis-2001.639}

Background Raloxifene (RLX) is a selective oestrogen receptor modulator (SERM) and exerts a positive estrogenic activity on bone and on serum lipids. The purpose of this randomised study was to access the effect of RLX on Bone Mineral Density (BMD) and on serum lipids in postmenopausal (PM) women with severe osteopenia and/or osteoporosis according to WHO criteria.

Objectives $100 \mathrm{PM}$ women were randomly assigned to either RLX $60 \mathrm{mg} /$ day $+600 \mathrm{mg}$ Calcium Carbonate (CC) (70 women) or $600 \mathrm{mg}$ of CC alone (30 women), as controls, for 12 months. The two groups of women had similar anthropometric data, mean age $(56,98 \pm 5,1 \mathrm{yrs})$ and mean postmenopausal age $(9,4$ $\pm 5,2$ yrs).

Methods BMD was measured at baseline and at 12 months of therapy, using DEXA (Hologic 1000 QDR) at Lumbar Spine (LS) and Lft Femur (FN)(neck). Serum total Cholesterol, LDL, HDL, triglycerides were measured at baseline, 6 and 12 months (photometric method). Results are expressed as percentage change from baseline. Statistics were done using t-test (unpaired).

Results Bone loss prevented only in the group of RLX. The BMD increased at LS $=+2,3( \pm 2,8) \%$ and at $\mathrm{FN}=1,4( \pm$ $2,6) \%$. In the group of controls the BMD diminished at LS $-1,2$ $( \pm 1,1) \%$ and at $\mathrm{FN}-1,5( \pm 2,4) \%$. The difference in BMD changes between the two groups was significant $(\mathrm{p}<0,05)$. There was no change in HDL, LDL and triglycerides in either group. Only Total Cholesterol decreased significantly $(\mathrm{p}<0,05)$ in RLX group. No clinically relevant effects on safety parameters (liver enzymes, hematologic variables and vital signs) were recorded.

Conclusion We conclude that RLX proved to be effective and safe in the prophylaxis and treatment of postmenopausal severe osteopenia and/or osteoporosis.

\section{SAT0153 VERTEBRAL DEFORMITIES IN RHEUMATOID ARTHRITIS: THE OSLO, TRURO, AND AMSTERDAM COLLABORATIVE STUDY}

${ }^{1} \mathrm{MC}$ Lodder, ${ }^{2} \mathrm{G}$ Haugeberg, ${ }^{1} \mathrm{WF}$ Lems, ${ }^{2} \mathrm{RE}$ Orstavik, ${ }^{1} \mathrm{BA}$ Dijkmans, ${ }^{2} \mathrm{TK}$ Kvien, ${ }^{3} \mathrm{AD}$ Woolf. ${ }^{1}$ Rheumatology, Vrije Universiteit Medical Centre, Amsterdam, The Netherlands; ${ }^{2}$ Rheumatology, Diakonhjemmet Hospital, Oslo, Norway; ${ }^{3}$ Rheumatology, Royal Cornwall Hospital, Truro, UK

\subsection{6/annrheumdis-2001.640}

\section{Background}

Objectives To determine the occurrence of vertebral deformities (VD) in a cross-sectional study of postmenopausal women with rheumatoid arthritis (RA). Secondly, associates for VD will be identified.

Methods A total of 150 female patients (50 per centre), aged between 50 and 70 years and a disease duration of 5 or more years, attending a general rheumatology clinic were consecutively included. Demographic and clinical data were collected according to a standardised procedure; bone fracture history, disease activity measures, hand X-rays (Larsen) and bone mineral density by means of dual energy X-ray absorptiometry of hip and lumbar spine. Lateral X-rays of thoracal and lumbar spine were read by one observer. Assessment was done as proposed by Genant. ${ }^{1}$ Associations between the presence of VD, and demographic, clinical and BMD variables were examined bivariately. The multivariate analysis was carried out using logistic regression.

Results Spine X-rays of 137 women were included in the analysis. Of these women 20 out of $137(14.6 \%)$ had at least one VD grade one or higher; $18 \%$ in Oslo, $10 \%$ in Amsterdam, and $16 \%$ in Truro. The table shows results of the bivariate analysis. Ever use of corticosteroids was not associated with VD ( $\mathrm{p}=$ $0.33)$.

Previous non-vertebral fracture after age 25 (as recalled by the patient) was the independent associate for VD in a logistic regression model containing age, weight, total Larsen score, nonvertebral fracture after age 25 and either femoral neck or spine BMD. Femoral neck BMD was independent variable in a model with age, weight, total Larsen score and femoral neck BMD. Age was the only independent associate of VD if femoral neck BMD was replaced by spine BMD in the latter model. The inclusion of corticosteroid use in either one of the models did not change the results.

\begin{tabular}{llllll}
\multicolumn{7}{c}{ Abstract SAT0153 Table 1 } \\
\hline $\begin{array}{l}\text { Age } \\
\text { (years) }\end{array}$ & $\begin{array}{l}\text { Non-vertebral } \\
\text { fracture }(\%)\end{array}$ & $\begin{array}{l}\text { Total Larsen } \\
\text { score } \\
(0-120)\end{array}$ & $\begin{array}{l}\text { Femoral neck } \\
\text { BMD }\left(\mathbf{g} / \mathrm{cm}^{2}\right)\end{array}$ & $\begin{array}{l}\text { Spine BMD } \\
\left(\mathbf{g} / \mathrm{cm}^{2}\right)\end{array}$ \\
\hline no & 60.7 & 21.6 & 37.9 & 0.81 & 1.07 \\
VD & & & & & \\
VD & 64.4 & 55.0 & 53.4 & 0.70 & 0.98 \\
p- & 0.009 & 0.02 & 0.03 & 0.006 & 0.05 \\
value & & & & & \\
\hline
\end{tabular}

Conclusion VD in a clinic population of RA patients was associated with either previous clinical fracture, femoral neck BMD or age as single independent variable dependent on the regression model applied. Studies on more patients allowing for larger regression models should further clarify the true associates of VD.

\section{REFERENCE}

1 Genant HK, et al. J Bone Miner Res. 1993;9:1137-48

\section{SAT0154 BISPHOSPHONATES AND UPPER GI PROBLEMS - WHAT IS THE EVIDENCE?}

${ }^{1}$ DC Bauer, ${ }^{2} \mathrm{~B}$ Cryor. ${ }^{1}$ Prevention Sciences Group, University of California, San Francisco, USA; ${ }^{2}$ University of Texas Southwestern Medical School, Dallas, USA

\subsection{6/annrheumdis-2001.641}

Background Upper gastrointestinal (UGI) tract mucosal irritation has been reported for a variety of bisphosphonates, including pamidronate, etidronate, clodronate, alendronate (ALN), tiludronate, and risedronate (RIS).

Objectives To use evidence-based medicine to rate and summarise the evidence regarding bisphosphonates and UGI problems. Methods Review and interpretation of published studies.

Results Although the clinical relevance of short-term, transient endoscopic findings is uncertain, one endoscopic study reported a higher incidence of gastric lesions for ALN vs RIS, and others reported no difference for ALN vs RIS or placebo. ${ }^{1-4}$ These 